\title{
Reply to: "The risk of malignancies in patients receiving hematopoietic stem cell transplantation: a systematic review and meta-analysis"
}

\author{
K. Heydari ${ }^{1,2} \cdot$ A. Shamshirian ${ }^{2,3} \cdot$ R. Alizadeh-Navaei ${ }^{2}$ (D
}

Received: 11 April 2020 / Accepted: 28 April 2020 / Published online: 15 May 2020

(c) Federación de Sociedades Españolas de Oncología (FESEO) 2020

We appreciate the interest and comments of Rezaeeniya on our systematic review and meta-analysis [1]. We searched PubMed, Web of Science, and Scopus databases and references list of our selected studies as an additional resource. We, of course, agree search in Embase database and using unpublished data like gray literature would be helpful but they are not essential for performing such studies. As it has been mentioned in Elsevier website, Scopus includes most of the contents of Embase, and reasonably can coverage the EMBASE database [2]. It is also remarkable that we have only access Scopus database through our university server. There are also many meta-analyses, which did not consider gray literature [3]. Decisions about whether to include grey literature in a state-of-the-evidence review are complex [4]. We also agree with Rezaeeniya regarding utilization reporting guideline and we used the PRISMA for this purpose but not mentioned in the text. There was data heterogeneity in our study and some other studies; in these cases, there are two approaches; (1) ignoring the meta-analysis and present all of the study results individually without combining them, or; (2) using random-effect model combined analysis [5]. Therefore, we used random-effect model for data synthesis. Publication bias occurs when studies which have statistically significant positive results get published and the negative result studies or studies without statistical insignificancy does not get published [6]. This concern about the result

This reply refers to the comment available online at https://doi. org/10.1007/s12094-020-02351-5.

R. Alizadeh-Navaei

Reza_nava@yahoo.com

1 Student Research Committee, School of Medicine, Mazandaran University of Medical Sciences, Sari, Iran

2 Gastrointestinal Cancer Research Center, Mazandaran University of Medical Sciences, Sari, Iran

3 Department of Medical Laboratory Sciences, Student Research Committee, School of Allied Medical Science, Mazandaran University of Medical Sciences, Sari, Iran of individual study does not seem to occur in the primary study of our systematic review, because these studies were not comparative studies. However, we will try to consider some of these suggestions for our future systematic reviews and meta-analysis.

\section{Compliance with ethical standards}

Conflict of interest The authors declare that they have no conflict of interest.

\section{References}

1. Heydari K, Shamshirian A, Lotfi-Foroushani P, Aref A, Hedayatizadeh-Omran A, Ahmadi M, Janbabei G, Keyhanian S, Zaboli E, Ghasemzadeh SM, Alizadeh-Navaei R. The risk of malignancies in patients receiving hematopoietic stem cell transplantation: a systematic review and meta-analysis. Clin Transl Oncol. 2020. https://doi.org/10.1007/s12094-020-02322-w.

2. Burnham JF. Scopus database: a review. Biomed Digit Libr. 2006;3:1.

3. McAuley L, Pham B, Tugwell P, Moher D. Does the inclusion of grey literature influence estimates of intervention effectiveness reported in meta-analyses? Lancet. 2000;356(9237):1228-311.

4. Benzies KM, Premji S, Hayden KA, Serrett K. State-of-theevidence reviews: advantages and challenges of including grey literature. Worldviews Evid Based Nurs. 2006;3(2):55-61.

5. Ahn E, Kang H. Introduction to systematic review and metaanalysis. Korean J Anesthesiol. 2018;71(2):103-12.

6. Nair AS. Publication bias-importance of studies with negative results! Indian J Anaesth. 2019;63(6):505-7.

Publisher's Note Springer Nature remains neutral with regard to jurisdictional claims in published maps and institutional affiliations. 